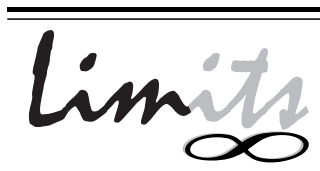

J. Math. and Its Appl.

ISSN : $1829-605 \mathrm{X}$

Vol. 8, No. 2, November 2011, 43-49

\title{
KAJIAN TEOREMA TITIK TETAP PEMETAAN KONTRAKTIF PADA RUANG METRIK CONE LENGKAP DENGAN JARAK- $W$
}

\author{
Sunarsini. ${ }^{1}$, Sadjidon $^{2}$ \\ Jurusan Matematika, FMIPA ITS Surabaya \\ ${ }^{1}$ sunarsini@matematika.its.ac.id, ${ }^{2}$ sadjidon@matematika.its.ac.id
}

\begin{abstract}
Abstrak
Ruang metrik adalah himpunan tak kosong yang dilengkapi dengan fungsi jarak. Jika range dari fungsi jarak (himpunan bilangan real) diganti dengan ruang Banach real, maka diperoleh pengertian ruang metrik cone. Pada paper ini diperkenalkan pengertian ruang metrik cone dengan jarak- $w$, yang merupakan hasil pengembangan dari ruang metrik cone. Selanjutnya, dikaji bahwa teorema titik tetap pemetaan kontraktif pada ruang metrik cone lengkap masih tetap berlaku pada ruang metrik cone lengkap dengan jarak- $w$.
\end{abstract}

Katakunci: Ruang metrik, Ruang metrik cone, Teorema titik tetap.

\section{Pendahuluan}

Analisis fungsional merupakan salah satu cabang matematika analisis klasik. Metode analisis fungsional sangat besar peranannya dalam berbagai bidang matematika dan aplikasinya. Dalam analisis fungsional dipelajari lebih umum tentang "ruang" dan "fungsi" yang terdefinisi padanya. Sebagai contoh, himpunan tak kosong yang dilengkapi dengan "fungsi jarak", dinamakan ruang metrik, kemudian ruang linear yang dilengkapi dengan "fungsi norm" dinamakan ruang norm [1]. 
Berbicara mengenai ruang metrik, Long-Guang [2], memperumum ruang metrik menjadi ruang metrik cone, yaitu dengan mengganti range fungsi jarak (himpunan bilangan real) menjadi ruang Banach real. Salah satu teorema yang terkait dengan ruang metrik dan menarik untuk diteliti adalah teorema titik tetap Banach atau teorema titik tetap pemetaan kontraktif. Teorema tersebut menjadi sumber penting dari teorema eksistensi dan ketunggalan dalam berbagai cabang analisis. Aplikasi dari teorema titik tetap inipun memegang peranan yang cukup besar, antara lain sistem persamaan linear, persamaan differensial biasa/parsial, persamaan integral dan lain-lain. Bertolak dari itulah, maka Long-Guang [2] memperumum teorema titik tetap Banach pada ruang metrik ke dalam ruang metrik cone. Pengembangan teorema titik tetap Banach pada ruang inipun banyak diteliti lebih lanjut, salah satunya dilakukan oleh Raja dan Vaezpour [3]. Dalam penelitiannya, Raja dan Vaezpour memperumum definisi pemetaan kontraktif menjadi c-nonexpansive dan $(c, \lambda)$-uniformly locally contractive functions f-closure, c-isometric pada ruang metrik cone lengkap. Berbeda dengan Raja dan Vaezpour, penelitian Lakzian dan Arabyani [4] terfokus pada pengembangan ruang metrik cone menjadi ruang metrik cone dengan jarak- $w$. Dengan analogi yang sama dari beberapa penelitian yang telah dilakukan oleh [4][2], tujuan utama dari paper ini adalah menunjukkan bahwa teorema titik tetap pemetaan kontraktif pada ruang metrik cone lengkap masih tetap berlaku pada ruang metrik cone lengkap dengan jarak- $w$.

\section{Ruang Metrik Cone Dengan Jarak- $w$}

Pada bagian ini dibahas tentang ruang metrik cone dengan jarak- $w$. Sebelumnya, didefinisikan pengertian cone, urutan parsial, cone normal dan ruang metrik cone. Beberapa contoh dan sifat-sifat yang terkait diberikan pula pada bagian ini.

Definisi 2.1 [2] Diberikan $E$ ruang Banach real dan $P \subseteq E$. $P$ disebut cone jika dan hanya jika

i. $P$ tertutup, $P \neq \varnothing$ dan $P \neq\{0\}$

ii. $a, b \in \mathbb{R}, a, b \geq 0, x, y \in P \rightarrow a x+b y \in P$

iii. $x \in P$ dan $(-x) \in P \Rightarrow x=0$

Berikutnya, jika $P \subseteq E$ cone, didefinisikan urutan parsial " $\preccurlyeq "$ terhadap $P$ dengan $x \preccurlyeq y$ jika hanya jika $y-x \in P$. Untuk $x \prec y$ diartikan $x \preccurlyeq y$ dan $x \neq y$. Untuk $x \ll y$ diartikan $y-x \in \operatorname{int} P$ (interior $\mathrm{P}$ ) [2].

Definisi 2.2 [2] $P$ disebut cone normal jika terdapat $K>0$ sehingga $\forall x, y \in E$ dengan $0 \leq x \leq y$ berakibat $\|x\| \leq K\|y\|$. 
Untuk selanjutnya, selalu diasumsikan bahwa $E$ ruang Banach real, $P$ cone dalam $E$ dengan int $P \neq \emptyset$ dan " $\preccurlyeq "$ adalah urutan parsial terhadap $P$.

Misalkan $X \neq \emptyset$. Fungsi $d: X \times X \rightarrow E$ sehingga memenuhi

i $0 \preccurlyeq d(x, y)$ untuk semua $x, y \in X$ dan $d(x, y)=0$ jika hanya jika $x=y$

ii $d(x, y)=d(y, x)$ untuk semua $x, y \in X$

iii $d(x, y) \preccurlyeq d(x, z)+d(y, z)$ untuk semua $x, y, z \in X$

disebut metrik cone pada $X$ dan $(X, d)$ disebut ruang metrik cone.

Contoh :

1. Misalkan $E=\mathbb{R}, P:=\{x \in E: x \geq 0\}, X=\mathbb{R}$ dan $d: X \times X \rightarrow E$ sehingga $d(x, y)=|x-y|$, maka $(X, d)$ ruang metrik cone.

2. Misalkan $E=\mathbb{R}^{2}, P:=\{(x, y) \in E: x, y \geq 0\}, X=\mathbb{R}$ dan $d: X \times X \rightarrow E$ sehingga $d(x, y)=(|x-y|, \alpha|x-y|)$ dengan $\alpha \geq 0$, maka $(X, d)$ ruang metrik cone.

Definisi 2.3 [4] Misalkan $X$ ruang metrik cone dengan metrik d, maka fungsi $p$ : $X \times X \rightarrow E$ disebut jarak-w pada $X$ jika memenuhi:

1. $0 \preccurlyeq p(x, y)$ untuk semua $x, y \in X$

2. $p(x, y) \preccurlyeq p(x, z)+p(y, z)$ untuk semua $x, y, z \in X$

3. $p(x,.) \rightarrow E$ lower semi kontinu untuk semua $x \in X$

4. untuk semua $0 \ll \alpha$, terdapat $0 \ll \beta$ sehingga $p(z, x) \ll \beta$ dan $p(z, y) \ll \beta$ berakibat $p(x, y) \ll \alpha$ dengan $\alpha, \beta \in E$.

Contoh :

1. Misalkan $(X, d)$ ruang metrik, maka $p=d$ merupakan jarak- $w$ pada $X$.

2. Misalkan $X$ ruang norm dengan norm Euclid, maka fungsi $p: X \times X \rightarrow[0, \infty)$ yang didefinisikan oleh $p(x, y)=\|x\|+\|y\|$ untuk semua $x, y \in X$ merupakan jarak- $w$ pada $X$.

Berikut ini didefinisikan pengertian barisan konvergen, barisan Cauchy pada ruang metrik cone dengan jarak- $w$.

Definisi 2.4 [4] Misalkan $(X, d)$ adalah ruang metrik cone, $p$ adalah jarak-w pada $X, x \in X$ dan $\left\{x_{n}\right\}$ barisan dalam $X$. 
a. $\left\{x_{n}\right\}$ disebut barisan Cauchy-p jika untuk setiap $\alpha \in E, 0 \ll \alpha$, terdapat bilangan asli $N$ sehingga untuk semua $m, n \geq N, p\left(x_{n}, x_{m}\right) \ll \alpha$.

b. Barisan $\left\{x_{n}\right\}$ dalam $X$ disebut konvergen-p ke $x \in X$ jika untuk setiap $\alpha \in E$, $0 \ll \alpha$, terdapat bilangan asli $N$ sehingga untuk semua $n \geq N, p\left(x, x_{n}\right) \ll$ $\alpha$. Karena $p$ lower semi-kontinu, maka untuk semua $n \geq N, p\left(x_{n}, x\right) \ll \alpha$. Dinotasikan $\lim _{n \rightarrow \infty} x_{n}=x$ atau $x_{n} \rightarrow x$.

c. $(X, p)$ disebut ruang metrik cone lengkap dengan jarak-w jika setiap barisan Cauchy-p dalam $X$ konvergen- $p$.

\section{Teorema Titik Tetap Pemetaan Kontraktif}

Pada bagian ini dibuktikan bahwa teorema titik tetap pemetaan kontraktif pada ruang metrik cone lengkap tetap berlaku pada ruang metrik cone lengkap dengan jarak- $w$. Sebelumnya, didefinisikan pengertian titik tetap dan pemetaan kontraktif pada ruang metrik.

Definisi 3.1 [1] Titik tetap dari pemetaan $T: X \rightarrow X$ adalah $x \in X$ yang dipetakan pada dirinya sendiri, artinya, $T x=x$.

Sebagai contoh : pemetaan $T: \mathbb{R} \rightarrow \mathbb{R}$ dengan $T x=x^{2}$ mempunyai dua titik tetap yaitu 0 dan 1 , translasi tidak mempunyai titik tetap, dan sebuah rotasi mempunyai satu titik tetap yaitu pusat dan rotasi.

Definisi 3.2 [1] Misalkan $X=(X, d)$ ruang metrik. Pemetaan $T: X \rightarrow X$ disebut kontraktif pada $X$ jika terdapat bilangan real positif $\alpha<1$ sehingga untuk semua $x, y \in X$ berlaku:

$$
d(T x, T y) \leq \alpha d(x, y)
$$

Teorema 3.3 [2] Misalkan $(X, p)$ ruang metrik cone lengkap dengan $p$ adalah jarak-w, $P$ cone normal pada $X$. Jika $T: X \rightarrow X$ memenuhi kondisi $p(T x, T y) \preccurlyeq$ $k p(x, y))$ untuk semua $x, y \in X$, dengan $k \in(0,1)$ suatu konstanta, maka $T$ mempunyai titik tetap tunggal dalam $X$. Untuk setiap $x \in X$ barisan iterasi $\left\{T^{n}(x)\right\}$ konvergen ke titik tetap tersebut.

Bukti Untuk setiap $x_{0} \in X$ dan $n \geq 1$ dibentuk barisan iterasi $T^{n}\left(x_{0}\right)$ dengan $x_{1}=T x_{0}, x_{2}=T x_{1}=T\left(T x_{0}\right)=T^{2} x_{0}, \ldots, x_{n+1}=T x_{n}=T^{n+1} x_{0}$, maka diperoleh

$$
\begin{aligned}
p\left(x_{n+1}, x_{n}\right) & =p\left(T x_{n}, T x_{n-1}\right) \preccurlyeq k p\left(x_{n}, x_{n-1}\right) \\
& \preccurlyeq k \cdot k p\left(x_{n-1}, x_{n-2}\right) \preccurlyeq \ldots \preccurlyeq k^{n} p\left(x_{1}, x_{0}\right)
\end{aligned}
$$


Menurut Definisi 2.3, untuk $n>m$ diperoleh

$$
\begin{aligned}
p\left(x_{n}, x_{m}\right) & \preccurlyeq p\left(x_{n}, x_{n-1}\right)+p\left(x_{n-1}, x_{n-2}\right)+\ldots+p\left(x_{m+1}, x_{m}\right) \\
& \preccurlyeq\left(k^{n-1}+k^{n-2}+\ldots+k^{m}\right) p\left(x_{1}, x_{0}\right)=k^{m} \frac{1-k^{n-m}}{1-k} p\left(x_{1}, x_{0}\right) .
\end{aligned}
$$

Karena $0 \leq k<1$ maka $1-k^{n-m} \leq 1$. Jadi $p\left(x_{n}, x_{m}\right) \preccurlyeq \frac{k^{m}}{1-k} p\left(x_{1}, x_{0}\right)$.

Misalkan $c \in E$ dengan $0 \ll c$, maka terdapatlah bilangan asli $N_{1}$ sehingga untuk semua $m \geq N_{1}$ berlaku $\left(\frac{k^{m}}{1-k}\right) p\left(x_{1}, x_{0}\right) \ll c$. Jadi $p\left(x_{n}, x_{m}\right) \ll c$, untuk semua $n>m$. Dengan kata lain $\left\{x_{n}\right\}$ barisan Cauchy- $p$ di $X$. Karena $X$ ruang metrik cone lengkap, berdasarkan Definisi 2.4, berakibat barisan $x_{n}$ konvergen- $p$, katakan konvergen ke $x^{*} \in X\left(x_{n} \rightarrow x^{*}, n \rightarrow \infty\right)$. Jadi dengan mengambil bilangan asli $N_{2}$ sehingga $p\left(x^{*}, x_{n}\right) \ll c / 2$ untuk semua $n \geq N_{2}$. Dengan demikian

$$
\begin{aligned}
p\left(T x^{*}, x^{*}\right) & \preccurlyeq p\left(T x^{*}, T x_{n}\right)+p\left(T x_{n}, x^{*}\right) \preccurlyeq k p\left(x^{*}, x^{n}\right)+p\left(x_{n+1}, x^{*}\right) \\
& \preccurlyeq p\left(x^{*}, x_{n}\right)+p\left(x_{x+1}, x^{*}\right) \ll \frac{c}{2}+\frac{c}{2}=c
\end{aligned}
$$

untuk semua $n \geq N_{2}$. Jadi $p\left(T x^{*}, x^{*}\right) \ll c / m$, untuk semua $m \geq 1$ atau $\frac{c}{m}-$ $p\left(T x^{*}, x^{*}\right) \in P$, untuk $m \geq 1$. Karena $c / m \rightarrow 0, m \rightarrow \infty$ dan $P$ tertutup, maka $-p\left(T x^{*}, x^{*}\right) \in P$. Menurut Definisi 2.1, $p\left(T x^{*}, x^{*}\right) \in P \operatorname{dan}-p\left(T x^{*}, x^{*}\right) \in P$ maka $p\left(T x^{*}, x^{*}\right)=0$. Jadi $T x^{*}=x^{*}$. Terbukti $x^{*}$ titik tetap dari $T$. Selanjutnya, jika $y^{*}$ titik tetap yang lain dari $T$, maka $p\left(x^{*}, y^{*}\right)=p\left(T x^{*}, T y^{*}\right) \preccurlyeq k p\left(x^{*}, y^{*}\right)$. Jadi $x^{*}=y^{*}$.

Dengan analogi yang sama dari Teorema 3.1 diperoleh dua teorema berikut, yang merupakan hasil utama dalam paper ini.

Teorema 3.4 [2] Misalkan $(X, p)$ ruang metrik cone lengkap dengan $p$ adalah jarak-w, $P$ cone normal pada $X$. Jika $T: X \rightarrow X$ memenuhi kondisi $p(T x, T y) \preccurlyeq$ $k(p(T x, y)+p(T y, x))$ untuk semua $x, y \in X$, dengan $k \in\left(0, \frac{1}{2}\right)$ suatu konstanta, maka $T$ mempunyai titik tetap tunggal dalam $X$. Untuk setiap $x \in X$ barisan iterasi $\left\{T^{n}(x)\right\}$ konvergen ke titik tetap tersebut.

Bukti Untuk setiap $x_{0} \in X$ dan $n \geq 1$ dibentuk barisan iterasi $T^{n}\left(x_{0}\right)$ dengan $x_{1}=T x_{0}, x_{2}=T x_{1}=T\left(T x_{0}\right)=T^{2} x_{0}, \ldots, x_{n+1}=T x_{n}=T^{n+1} x_{0}$, , maka diperoleh

$$
\begin{aligned}
p\left(x_{n+1}, x_{n}\right) & =p\left(T x_{n}, T x_{n-1}\right) \preccurlyeq k\left(p\left(T x_{n}, x_{n}\right)+p\left(T x_{n-1}, x_{n}\right)\right) \\
& =k\left(p\left(x_{n+1}, x_{n-1}\right)+p\left(x_{n}, x_{n}\right)\right)=k\left(p\left(x_{n+1}, x_{n-1}\right)\right) \\
& \preccurlyeq k\left(p\left(x_{n+1}, x_{n}\right)+p\left(x_{n}, n_{n-1}\right)\right)(\text { karena } p \text { adalah jarak- } w \text { pada } X)
\end{aligned}
$$

Jadi $p\left(x_{n+1}, x_{n}\right) \preccurlyeq \frac{k}{1-k} p\left(x_{n}, x_{n-1}\right)=h p\left(x_{n}, x_{n-1}\right)$ dengan $h=\frac{k}{1-k}$.

Untuk $n>m$,

$$
\begin{aligned}
p\left(x_{n}, x_{m}\right) & \preccurlyeq p\left(x_{n}, x_{n-1}\right)+p\left(x_{n-1}, x_{n-2}\right)+\ldots+p\left(x_{m+1}, x_{m}\right) \\
& \preccurlyeq\left(h^{n+1}+h^{n-2}+\ldots+h^{m}\right) p\left(x_{1}, x_{0}\right) \preccurlyeq h^{m} \frac{1-h^{n-m}}{1-h} p\left(x_{1}, x_{0}\right)
\end{aligned}
$$


Karena $0 \leq k<1$ maka $0 \leq h<1$. Jadi $p\left(x_{n}, x_{m}\right) \preccurlyeq \frac{h^{m}}{1-h} p\left(x_{1}, x_{0}\right)$.

Misalkan $c \in E$ dengan $0 \ll c$, maka terdapatlah bilangan asli $N_{1}$ sehingga untuk semua $m \geq N_{1}$ berlaku $\left(\frac{h^{m}}{1-h}\right) p\left(x_{1}, x_{0}\right) \ll c$. Jadi $p\left(x_{n}, x_{m}\right) \ll c$, untuk semua $n>m$. Dengan kata lain $\left\{x_{n}\right\}$ barisan Cauchy- $p$ di $X$. Karena $X$ ruang metrik cone lengkap, berdasarkan Definisi 2.4, maka $\left\{x_{n}\right\}$ konvergen- $p$, katakan konvergen ke $x^{*} \in X\left(x_{n} \rightarrow x^{*}, n \rightarrow \infty\right)$. Jadi dengan mengambil bilangan asli $N_{2}$ sehingga $p\left(x^{*}, x_{n}\right) \ll c / 3$ untuk semua $n \geq N_{2}$. Dengan demikian

$$
\begin{aligned}
p\left(T x^{*}, x^{*}\right) & \preccurlyeq p\left(T x^{*}, T x_{n}\right)+p\left(T x_{n}, x^{*}\right) \preccurlyeq k\left(p\left(T x^{*}, x^{n}\right)+p\left(T x_{n}, x^{*}\right)\right)+p\left(T x_{n}, x^{*}\right) \\
& \preccurlyeq p\left(x^{*}, x_{n}\right)+p\left(x_{x+1}, x^{*}\right)+p\left(x_{n+1}, x^{*}\right) \ll \frac{c}{3}+\frac{c}{3}+\frac{c}{3}=c
\end{aligned}
$$

untuk semua $n \geq N_{2}$. Jadi $p\left(T x^{*}, x^{*}\right) \ll c / m$, untuk semua $m \geq 1$ atau $\frac{c}{m}-$ $p\left(T x^{*}, x^{*}\right) \in P$, untuk $m \geq 1$. Karena $c / m \rightarrow 0, m \rightarrow \infty$ dan $P$ tertutup, maka $-p\left(T x^{*}, x^{*}\right) \in P$. Menurut Definisi $2.1, p\left(T x^{*}, x^{*}\right) \in P$ dan $-p\left(T x^{*}, x^{*}\right) \in P$ maka $p\left(T x^{*}, x^{*}\right)=0$. Jadi $T x^{*}=x^{*}$. Terbukti $x^{*}$ titik tetap dari $T$. Selanjutnya, jika $y^{*}$ titik tetap yang lain dari $T$, maka $\left(x^{*}, y^{*}\right)=p\left(T x^{*}, T y^{*}\right) \preccurlyeq k\left(p\left(T x^{*}, y^{*}\right)+\right.$ $\left.p\left(T y^{*}, x^{*}\right)\right)=2 k p\left(x^{*}, y^{*}\right)$. Jadi $p\left(x^{*}, y^{*}\right)=0, x^{*}=y^{*}$. Dengan demikian terbukti bahwa $T$ mempunyai titik tetap tunggal dalam $X$.

Teorema 3.5 [2] Misalkan $(X, d)$ ruang metrik cone lengkap dengan $p$ adalah jarak-w, $P$ cone normal pada $X$ dengan konstanta $K$. Jika $T: X \rightarrow X$ memenuhi kondisi $p(T x, T y) \preccurlyeq k(p(T x, x)+p(T y, y))$ untuk semua $x, y \in X$, dengan $k \in$ $\left(0, \frac{1}{2}\right)$ suatu konstanta, maka $T$ mempunyai titik tetap tunggal dalam $X$. Untuk setiap $x \in X$ barisan iterasi $\left\{T^{n}(x)\right\}$ konvergen ke titik tetap tersebut.

Bukti Untuk setiap $x_{0} \in X$ dan $n \geq 1$ dibentuk $x_{1}=T x_{0}, x_{2}=T x_{1}=$ $T\left(T x_{0}\right)=T^{2} x_{0}^{\prime} \ldots, x_{n+1}=T x_{m}=T^{n+1} x_{0}$, maka diperoleh

$$
\begin{aligned}
p\left(x_{n+1}, x_{n}\right) & =p\left(T x_{n}, T x_{n-1}\right) \preccurlyeq k\left(p\left(T x_{n}, x_{n}\right)+p\left(T x_{n-1}, x_{n-1}\right)\right) \\
& =k\left(p\left(x_{n+1}, x_{n}\right)+p\left(x_{n}, x_{n-1}\right)\right) \\
p\left(x_{n+1}, x_{n}\right) & -k\left(p\left(x_{n+1}, x_{n}\right)\right) \preccurlyeq p\left(x_{n}, x_{n-1}\right) \\
p\left(x_{n+1}, x_{n}\right) & \preccurlyeq \frac{k}{1-k} p\left(x_{n}, x_{n-1}\right)=h p\left(x_{n}, x_{n-1}\right) \text { dengan } h=\frac{k}{1-k} .
\end{aligned}
$$

Menurut Definisi 2.3, untuk $n>m$ diperoleh

$$
\begin{aligned}
p\left(x_{n}, x_{m}\right) & \preccurlyeq p\left(x_{n}, x_{n-1}\right)+p\left(x_{n-1}, x_{n+2}\right)+\ldots+p\left(x_{m+1}, x_{m}\right) \\
& \preccurlyeq\left(h^{n-1}+h^{n-2}+\ldots+h^{m}\right) p\left(x_{1}, x_{0}\right) \preccurlyeq \frac{h^{m}}{1-h} p\left(x_{1}, x_{0}\right)
\end{aligned}
$$

Karena $P$ normal cone, maka menurut Definisi 2.2 terdapatlah konstanta $K>0$, sehingga $\left\|p\left(x_{n}, x_{m}\right)\right\| \leq \frac{h^{m}}{1-h} K\left\|p\left(x_{1}, x_{0}\right)\right\|$. Akibatnya, $p\left(x_{n}, x_{m}\right) \rightarrow 0(n, m \rightarrow \infty)$. Jadi $x_{n}$ barisan Cauchy- $p$ di $X$. Karena $X$ ruang metrik cone lengkap dengan 
jarak- $w$ maka barisan Caunchy- $p$ di dalam $X$ konvergen- $p$, katakan konvergen ke $x^{*} \in X\left(x_{n} \rightarrow x^{*}, n \rightarrow \infty\right)$.

Karena

$$
\begin{gathered}
p\left(T x^{*}, x^{*}\right) \preccurlyeq p\left(T x_{n}, T x^{*}\right) \preccurlyeq k\left(p\left(T x_{n}, x_{n}\right)+p\left(T x^{*}, x^{*}\right)\right)+p\left(x_{n+1}, x^{*}\right) \\
p\left(T x^{*}, x^{*}\right) \preccurlyeq \frac{1}{1-k}\left(k p\left(T x_{n}, x_{n}\right)+p\left(x_{n+1}, x^{*}\right)\right) \\
\left\|p\left(T x^{*}, x^{*}\right)\right\| \leq K \frac{1}{1-k}\left(k\left\|p\left(T x_{n}, x_{n}\right)\right\|+\left\|p\left(x_{n+1}, x^{*}\right)\right\|\right) \rightarrow 0
\end{gathered}
$$

Jadi, $\left\|p\left(T x^{*}, x^{*}\right)\right\|=0$. Hal ini berakibat $T x^{*}=x^{*}$ atau $x^{*}$ titik tetap dari $T$. Tinggal menunjukkan ketunggalannya. Jika $y^{*}$ titik tetap yang lain dari $T$, maka $p\left(x^{*}, y^{*}\right)=p\left(T x^{*}, t y^{*}\right) \leq k\left(p\left(T x^{*}, x^{*}\right)+p\left(T y^{*}, y^{*}\right)\right)=0$. Jadi $x^{*}=y^{*}$.

\section{Penutup}

Dari pembahasan di atas dapat disimpulkan bahwa teorema titik tetap pemetaan kontraktif tetap berlaku pada ruang metrik cone lengkap maupun ruang metrik cone lengkap dengan jarak- $w$.

\section{Pustaka}

[1] Kreyszig, E., Introductory Functional Analysis with Application, John Wiley and Sons. Inc., New York, 1978.

[2] Long-Guang, H., and Xian, Z, Cone Metric Spaces and Fixed Point Theorems of Contractive Mappings, Journal Mathematical Analysis and Applications, 332, 1468-1476, 2007.

[3] Raja, P., And Vaezpour, S.M.,, Some Extensions of Banach's Contraction Principle in Complete Cone Metric Spaces, Hindawi Publishing Corporation Fixed Point Theory and Applications, article ID 768294, 11 pages, 2008.

[4] Lakzian, H., and Arabyani, F., Some Fixed Point Theorems in Cone Metric Spaces with w-Distance, Int. Journal of Math. Analysis, vol. 3, no. 22, 1081-1086, 2009 